\title{
Chlamydia prevalence in the general population: is there a sex difference? a systematic review
}

\author{
Patrick W Dielissen ${ }^{1 *}$, Doreth AM Teunissen ${ }^{1,2}$ and Antoine LM Lagro-Janssen ${ }^{1,2}$
}

\begin{abstract}
Background: The focus of Chlamydia trachomatis screening and testing lies more on women than on men. The study aim was to establish by systematic review the prevalence of urogenital Chlamydia trachomatis infection in men and women in the general population.

Methods: Electronic databases and reference lists were searched from 2000 to 2013 using the key words "Chlamydia trachomatis", "population-based study" and "disease prevalence". Reference lists were checked. Studies were included in the analysis if Chlamydia trachomatis prevalence was reported for both men and women in a population-based study. Prevalence rates for men and women were described as well as highest prevalence rate by age and sex. The difference in prevalence between the sexes in each study was calculated.

Results: Twenty-five studies met the inclusion criteria and quality assessment for the review. In nine of the twenty-five studies there was a statistically significant sex difference in the chlamydia prevalence. In all nine studies the prevalence of chlamydia was higher in women than in men. The prevalence for women varied from $1.1 \%$ to $10.6 \%$ and for men from $0.1 \%$ to $12.1 \%$. The average chlamydia prevalence is highly variable between countries. The highest prevalence of chlamydia occurred predominantly in younger age groups ( $<25$ years). The absence of symptoms in population-based urogenital chlamydia infection is common in men and women (mean 88.5\% versus 68.3\%).
\end{abstract}

Conclusions: The urogenital chlamydia trachomatis prevalence in the general population is more similar than dissimilar for men and women. A modest sex difference is apparent. The prevalence rates can be used to inform chlamydia screening strategies in general practice.

Keywords: Chlamydia trachomatis, Prevalence, General population, Gender

\section{Background}

Urogenital Chlamydia trachomatis represents one of the most common bacterial sexually transmitted infections (STIs) globally. The infection is mostly asymptomatic, easily tested and single-dose treatments of oral antibiotics are readily available [1]. Early diagnosis and treatment are important to avoid transmission to partners and to prevent complications. Left untreated it can have significant and long-term complications, particularly in women. These include pelvic inflammatory disease, ectopic pregnancy, tubal factor infertility and chronic pelvic pain $[2,3]$. The role for this pathogen in the development of male epididymitis and orchitis is widely accepted [4]. In (chronic) prostatitis the exact role is

\footnotetext{
* Correspondence: Patrick.Dielissen@radboudumc.nl

1 Department of Primary care and Community Care, Radboud University

medical center, P.O. Box 9101, Nijmegen 6500HB, The Netherlands

Full list of author information is available at the end of the article
}

still under debate because of the technical difficulties in localizing Chlamydia trachomatis to the prostate [5].

Lack of patient knowledge about chlamydia and/or the absence of symptoms of most chlamydia infections means that two important stimuli for seeking health care are absent [6-8]. Opportunistic screening is essential if control of this infection is to be achieved. Although there is an absence of evidence about the benefits of opportunistic chlamydia screening in the general population active case-finding for chlamydia is recommended $[2,9,10]$. General practitioners (GPs) attend to the majority of STI consultations and are the first point of contact with the health care system for most individuals in many countries and therefore ideally placed to screen patients [11,12]. Prevalence studies in the general population are important to investigate the occurrence of chlamydia infections in the population served by

\section{Biomed Central}


GPs and can be used to guide the focus of screening activities.

The research and screening is more focused on females, with the burden of disease and infertility considered to be a predominantly female problem $[9,13]$. For example, annual screening for all sexually active women $<25$ years is recommend in the US for women and not for men [14]. In many countries, women are more the target of chlamydia screening in the general population, reducing morbidity in women and not in men [10,15-17]. Emerging evidence suggests also an effect of a chlamydia infection on male fertility although more well-designed studies are required to prove a causal factor of chlamydia infection [4]. Women are more the focus of chlamydia control activities because they have more contact with health care related to sexual health i.e. cervix smear, oral contraception, pregnancy and IUD insertion [18]. Also, women have a higher uptake rate in chlamydia screening programmes $[19,20]$. For example, in a register based screening programme in the Netherlands, the participation rate was significantly higher among women $(21 \%)$ than among men (10.4\%) [21]. Last, in the literature, for various reasons women are still more than men considered biologically and psychosocially susceptible to chlamydia infection [22,23].

Non-population-based systematic reviews have consistently shown that the pooled prevalence of genital chlamydia between males and females is similar $[16,24,25]$. A systematic review and meta-analysis conducted in Australia found a pooled prevalence for women < 25 years of $5 \%$ (95 CI 3.1,6.9) and a pooled prevalence for men < 30 years of 3.9\% (95 CI 2.7,5.1) in community and general practice settings. Most studies included in these reviews do not compare men and women directly in a community setting or do not report the data separately [25]. The reviews also indicated important gaps of the knowledge about chlamydia prevalence particularly in men and in the general population. For example, in a systematic review of prevalence studies in the United Kingdom, only $11 \%$ of the reported prevalence estimates were from males [24]. Asymptomatic men are under-identified in these studies and they probably play an important role in sustaining the transmission of chlamydia in the population.

While Chlamydia trachomatis infection is an important public health issue for women, it is probably not without importance for men. The need for robust chlamydia estimates among women and men in the general population are essential to help elucidate the burden of infection. If required, GPs' awareness of a chlamydia infection and sensitivity for active case-finding in both women and men should be increased. This systematic review examines the available literature on the prevalence of genital Chlamydia trachomatis infection in the general population in studies that directly compare men and women.

\section{Methods}

\section{Search strategy}

We performed a search of the literature in the electronic bibliographic databases PubMed, Embase and CINAHL for English-language articles published between January 1, 2000 and December 31, 2012. The following search terms were used: "Chlamydia trachomatis" AND "prevalence" AND "population-based study OR population". Reference lists of included articles were checked for potential studies. Also, the reference lists of selected systematic reviews were hand-searched for further publications of interest $[16,24,25]$. A flow chart of the search is shown in Figure 1.

\section{Inclusion and exclusion criteria}

Studies were eligible for inclusion in the review if they (1) unambiguously reported prevalence of Chlamydia trachomatis infection in the general population, (2) compared and reported the chlamydia prevalence among men and women, (3) reported data from a population that was described as non-medical or non-health-care setting, (4) used nucleic acid amplification tests (NAAT) for diagnostic testing and (5) used a cross-sectional study design. We excluded articles that (1) reported only on men or women, (2) reported on selective populations, for example commercial sex workers, soldiers, ethnic groups, gynaecological patients or follow-up, (3) reported on prevalence among individuals with urogenital symptoms and (4) used serology for diagnosis. The first author (PD) applied the inclusion criteria to potentially eligible studies.

\section{Methodological assessment of reviewed studies}

The studies were assessed and information extracted by two authors independently (PD, DT). Disagreements were resolved by discussion and consensus with the third author (TLJ). To assess the usefulness of the prevalence studies four questions were required to be answered affirmatively [26,27]: (1) is the problem being studied in the general population with data obtained from registers or data administrations independently from a health care setting?; (2) Is the study's sampling design fully described?; (3) Was a probabilistic sample used?; (4) Is prevalence broken down by sex? Further assessment of the quality of the studies included the response rate of the total sample and sex subgroups (major flaw if < 40\%), reporting number screened, reporting of prevalence type and total prevalence, prevalence in subgroups and precision of estimation (95\% CI, error) [26]. If necessary, authors were contacted 


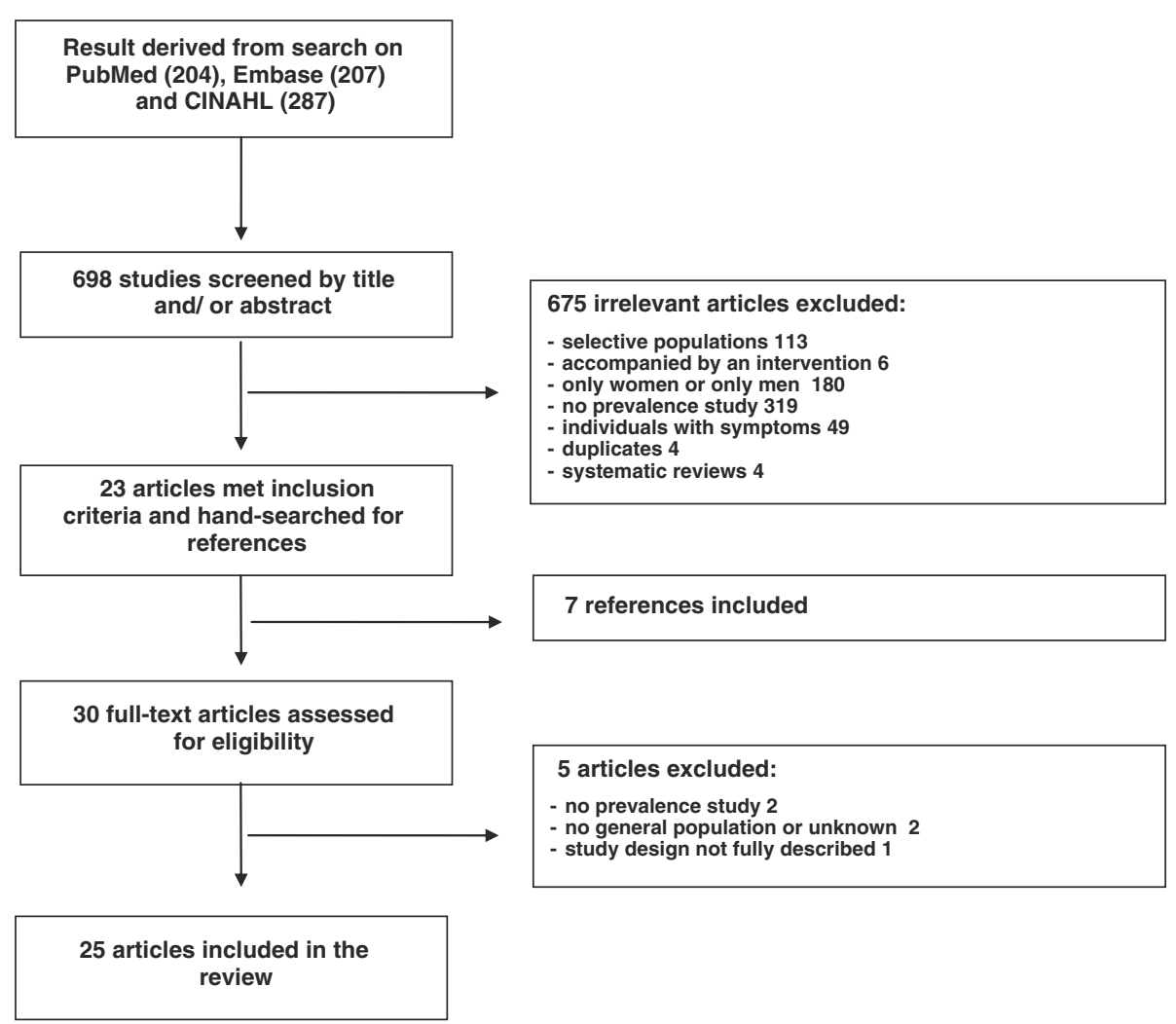

Figure 1 Flowchart of search, inclusions and exclusions from the systematic review.

by email for additional information for example the origin of the registries or administration database $[28,29]$.

The prevalence for both men and women, and if available the highest prevalence rate by age and sex, were extracted. We calculated the difference in prevalence between the sexes for each study and its 95\% confidence intervals [30]. The data were not pooled for meta-analysis. It was likely that there would be considerable heterogeneity between studies making any formal meta-analysis less valid. Also, it was not considered important to the interpretation of the data because of the different geographical location of each study and therefore of limited clinical added value of this pooled prevalence rate to GPs.

\section{Results}

\section{Description of included studies}

Our literature searches identified 698 studies which were screened by title and abstract. The full text of thirtyseven articles was read and fourteen were excluded. Of the remaining twenty-three articles the reference lists were searched and we included seven additional studies. Thirty studies were assessed for eligibility. Twentyfive articles were included in the review. (Figure 1 and Table 1).
The majority of the included studies were conducted in the general community (18), three were conducted in general practice $[19,31,40]$ and four in schools $[35,42,46,51]$. We included the studies that recruited participants from general practices in the Netherlands and the UK because in these countries the vast majority of its population is registered at one general practice [53]. We included studies from Europe (13) $[19,28,29,31,32,38-40,44,47,49,51,52]$, the United States of America (6) [34,35,41,42,45,50], Asia [36,46,48], Africa [33], Australia [37] and the Caribbean [43].

Study sample sizes were moderate. The number of individuals tested in each study varied considerably, ranging between 123 and 7555 participants. In all studies but two the number of female participants was higher than male participants [28,33]. Most studies reported 95\% confidence intervals for their prevalence rates of chlamydia infection in men and women but only ten studies conducted adequately statistically comparison of prevalence rate by sex $[28,33,35,36,38,39,43,45,49,50]$. Also, the age groups chosen varied considerably, including individuals at puberty or adolescence to adulthood (minimum 12 years and maximum 67 years). The response rates varied in men from $11.9 \%$ to $79.0 \%$ and in women from $18.9 \%$ to $86.0 \%$. Where reported, response rate in all studies was higher for women than for men. Only 
Table 1 Characteristics population-based studies reporting prevalence of Chlamydia trachomatis for both men and women

\begin{tabular}{|c|c|c|c|c|c|c|c|c|c|}
\hline Authors (publication year) [Reference] & Country & Men tested & Women tested & Response rate & Sampling & Test $\mathrm{M}$ & Test $\mathrm{F}$ & Invitation & Geographic area \\
\hline Valkengoed (2000) [31] & Netherlands & 1908 & 2902 & M 33.0\% F 51.0\% & General practices & PCR urine & PCR urine & By mail & Urban \\
\hline Fenton (2001) [32] & UK & 1474 & 2055 & Total $71.0 \%$ & General community & LCR urine & LCR urine & By mail & General population \\
\hline Obasi (2001) [33] & Tanzania & 4749 & 4686 & Total 80\% & General community & PCR urine & PCR urine & By interviewer & Rural \\
\hline Turner(2002) [34] & USA & 244 & 335 & Total 79.5\% & General community & LCR urine & LCR urine & By interviewer & Urban \\
\hline Miller (2004) [35] & USA & 6767 & 7555 & Total 87.6\% & Schools & LCR urine & LCR urine & By interviewer & Urban and rural \\
\hline Joyee (2004) [36] & India & 603 & 841 & NS & General community & PCR urine & PCR urine & By interviewer & Urban and rural \\
\hline Latif (2004) [37] & Australia & 525 & 694 & M 43.1\% F 56.9\% & General community & PCR FVU & PCR WS & By interviewer & Rural \\
\hline Klavs (2004) [29] & Slovenia & 683 & 764 & M 50.9\% F 60.0\% & General community & PCR urine & PCR urine & By interviewer & General population \\
\hline Bergen (2005) [38] & Netherlands & 2930 & 5453 & M 33.0\% F 47.0\% & General community & PCR urine & PCR urine & By mail & Urban and rural \\
\hline Götz (2005) [39] & Netherlands & 1999 & 4304 & Total $41.0 \%$ & General community & PCR urine & PCR urine & By mail & Urban and rural \\
\hline Macleod (2005) [40] & UK & 1930 & 2801 & M 26.6\% F 36.4\% & General practices & PCR urine & PCR urine WS & By mail & Urban and rural \\
\hline Low (2007) [19] & UK & 1396 & 1869 & M 29.5\% F 39.5\% & General practices & PCR urine & PCR WS & By mail & Urban \\
\hline Deblina Datta (2007) [41] & USA & 3096 & 3536 & Total 83.0\% & General community & LCR urine & LCR urine & By interviewer & General population \\
\hline Stein (2008) [42] & USA & 5074 & 5854 & Total 88.6\% & Schools & LCR urine & LCR urine & By interviewer & NS \\
\hline Adams (2008) [43] & Barbados & 190 & 207 & M 79.0\% F 86.0\% & General community & PCR urine & PCR urine & By interviewer & NS \\
\hline Uusküla (2008) [44] & Estonia & 215 & 345 & M 32.0\% F 48.0\% & General community & PCR FVU & PCR WS & By mail & Urban and rural \\
\hline Beydoun (2010) [45] & USA & 2447 & 3164 & NS & General community & NAAT urine & NAAT urine & By interviewer & NS \\
\hline Imai (2010) [46] & Japan & 2595 & 4003 & Total 81.5\% & Schools & PCR urine & PCR urine & By interviewer & NS \\
\hline Goulet (2010) [47] & France & 1135 & 1445 & M 65.0\% F 71.0\% & General community & PCR urine & PCR WS & By interviewer & Urban and rural \\
\hline Parish (2011) [48] & China & 1138 & 1235 & Total 69.0\% & General community & LCR urine & LCR urine & By interviewer & Urban and rural \\
\hline Desai (2011) [28] & Germany & 952 & 855 & NS & General community & NAAT urine & NAAT urine & NS & General population \\
\hline Bozicevic (2011) [49] & Croatia & 123 & 151 & M 27.9\% F 37.5\% & General community & PCR urine & PCR urine & By interviewer & Urban and rural \\
\hline Eggleston (2011) [50] & USA & 798 & 1322 & M 17.7\% F 26.5\% & General community & NAAT urine & NAAT urine & By interviewer & Urban \\
\hline Gravningen (2012) [51] & Norway & 466 & 565 & M 28.8\% F 34.9\% & Schools & PCR FVU & PCR FVU & Class-wise & Rural \\
\hline Klovstad (2012) [52] & Norway & 605 & 930 & M 11.9\% F 18.9\% & General community & NAAT FVU & NAAT FVU & By mail & Urban and rural \\
\hline
\end{tabular}

NS: data not stated.

PCR: polymerase chain reaction.

LCR: ligase chain reaction.

FVU: first voided urine.

VS: vulvovaginal swab.

NAAT: nucleic acid amplification technique for example, DBProbeTec amplified DNA assay and APTIMA Combo2 assay. 
eleven studies reported total response (31.5\% to $88.6 \%$ ) $[32-35,39,41,42,46,48,50,51]$. In three studies the total response rate or response rate for men and women separately was below 40\% (major flaw) [19,40,49]. In four studies the response rate for men was below $40 \%$ only $[31,38,44,52]$. Of the seven studies reporting low participation rates, six studies invited participants by mail $[19,31,38,40,44,49,52]$.

The most commonly utilized sample was urine or first voided urine for both men and women. First voided urine samples were tested for all of the male population. For women, in five studies a self-obtained lower vaginal swab was used or offered $[19,29,40,44,47]$. The prevalence of symptoms was reported in only eight studies $[19,33,35,38,42-44,52]$.

\section{Prevalence of chlamydia infection by sex}

The reported prevalence of chlamydia infection among men and women in population-based settings in various countries was diverse, ranging from $0.1 \%$ to $12.1 \%$ in men and from $1.1 \%$ to $10.6 \%$ in women. Table 2 shows the prevalence of the included studies by sex and the calculated difference in prevalence between the sexes of each study. We found a statistically significant difference in chlamydia prevalence in nine studies $[28,33-35,38,42,44,46,51]$. The study characteristics of these nine studies did not differ from the other studies in terms of geographic area, number of participants tested, age or response rate. Black women and men were disproportionately affected. Three studies reported particularly high chlamydia prevalence in black participants compared to nonblack participants with rates generally higher in women than in men [34,35,38]. For example, Miller et al. found a chlamydia prevalence in black men of $11.12 \%$ and in black women of $13.95 \%$ compared to a prevalence in white men of $1.38 \%$ and in white women of $2.52 \%$ [35].

In urban settings, chlamydia prevalence for women ranged from $2.8-6.2 \%$ and for men from 1.6-5.3\% (Table 2). In rural settings, chlamydia prevalence for women ranged from 1.6-7.3\% and for men from 1.0-3.9\%. Prevalence rate for women was highest in a study with participants aged 15-20 years. Ten studies reported on chlamydia prevalence estimates from studies conducted in rural and urban settings. Chlamydia prevalence for women ranged from 1.1-6.9\% and for men from 1.2$7.3 \%$. Highest prevalence rates in women and men were in studies with predominantly adolescents and small sample sizes.

The five studies that used self-obtained vaginal swabs in women and first voided urine in men, found no statistically significant difference in chlamydia prevalence in men and women (Table 2) $[19,37,40,44,47]$. Reported prevalence estimates were $1.6-6.9 \%$ for women and
$1.4-5.3 \%$ for men. In sixteen studies first voided urine was used in both women and men as test specimen. In these studies, chlamydia prevalence in women ranged from $1.1-10.6 \%$ and in men from $0.1-12.1 \%$.

\section{Prevalence of chlamydia infection by sex and age group}

Age-specific rates of chlamydia prevalence were reported in fourteen studies (Table 3) [29,31-33,36,38,40-42,45, $47,48,51,52]$. Unfortunately, the reporting of chlamydia prevalence among the different age groups was diverse and the studies used variable age groups making comparison between studies difficult. For example, not all studies restricted age groups to cohorts of five years.

Overall, in both men and women young age groups $(<25$ years) have higher chlamydia prevalence rates than older age groups but chlamydia prevalence in young age groups is not different for men and women. In six studies the highest prevalence of chlamydia infection was in the same age group for men and women $[29,31,40,45,51,52]$. In five studies women compared to men had the highest chlamydia prevalence at a younger age group $[32,36,38,41,47]$.

Furthermore, in all fourteen studies but two, the highest chlamydia prevalence occurred among participants $<25$ years of age; in women ranging from 2.1$6.6 \%$ and in men from 1.0-6.3\%. In two studies the highest age group was $>25$ years in both men and women. One study, originated from India, reported the highest chlamydia prevalence in men $31-45$ years of age and in women $31-35$ years of age $(2.1 \%$ versus $1.9 \%)$. In a study from China, the highest chlamydia prevalence was found in men aged 25-34 years and in women aged $35-44$ years (3.9\% versus $4.2 \%$ ) [36,48].

\section{The presence of symptoms by sex}

There were eight studies that reported information on the presence of symptoms among individuals tested $[19,33,35,38,42-44,52]$. The absence of symptoms in urogenital chlamydia infections varied in men from $73.9 \%$ to $94.6 \%$ and in women from $45.3 \%$ to $95.5 \%$. In all studies but one [35], the absence of symptoms was higher in men than in women.

\section{Discussion}

\section{Statement of the principal findings}

In our systematic review of 25 studies, we found modest sex differences in the prevalence of chlamydia infection between men and women in the general population. The prevalence for women varied from $1.1 \%$ to $10.6 \%$ and for men from $0.1 \%$ to $12.1 \%$. Nine out of twenty-five studies showed a statistically significant higher prevalence of chlamydia among women compared to men. The majority of the included studies did not found a sex difference. Where studies reported age-based estimates, 
Table 2 Results population-based studies reporting prevalence of Chlamydia trachomatis for both men and women

\begin{tabular}{|c|c|c|c|c|c|c|}
\hline $\begin{array}{l}\text { Authors (publication year) } \\
\text { [Reference] }\end{array}$ & $\begin{array}{l}\text { Overall } \\
\%(95 \% \mathrm{Cl})\end{array}$ & $\begin{array}{l}\text { Men } \\
\%(95 \% \mathrm{Cl})\end{array}$ & $\begin{array}{l}\text { Women } \\
\%(95 \% \mathrm{Cl})\end{array}$ & $\begin{array}{l}\text { Prevalence difference } \\
\text { by sex ( } p \text { or OR) }\end{array}$ & $\begin{array}{c}\text { Calculated risk } \\
\text { difference by sex (M-F) }\end{array}$ & $95 \% \mathrm{Cl}$ \\
\hline Valkengoed (2000) [31] & NS & $2.4(1.7-3.0)$ & $2.8(2.2-3.4)$ & NS & -0.4 & $-1.31 ; 0.51$ \\
\hline Fenton (2001) [32] & NS & $2.2(1.5-3.2)$ & $1.5(1.1-2.1)$ & NS & 0.7 & $-0.21 ; 1.62$ \\
\hline Obasi (2001) [33] & 1.8 (NS) & $1.0(0.8-1.4)$ & $2.4(2.3-2.9)$ & OR 2.4 (NS) & -1.4 & $-1.92 ;-0.88+$ \\
\hline Turner(2002) [34] & 3.0 (SE 0.8) & $1.6(\mathrm{NS})$ & 4.3 (NS) & NS & -2.7 & $-5.38 ;-0.02 \dagger$ \\
\hline Miller (2004) [35] & $4.2(3.5-4.9)$ & $3.7(2.9-4.6)$ & $4.7(3.9-5.7)$ & OR 1.3(1.0-1.6) & -1.0 & $-1.66 ;-0.34 \dagger$ \\
\hline Joyee (2004) [36] & $1.1(0.5-1.7)$ & $1.2(0.4-2.0)$ & $1.1(0.5-1.7)$ & $P>0.05$ & 0.1 & $-1.02 ; 1.22$ \\
\hline Latif (2004) [37] & 9.6 (NS) & 9.0 (NS) & 10.0 (NS) & NS & -1.0 & $-4.02 ; 2.02$ \\
\hline Klavs (2004) [29] & NS & $3.0(1.9-4.6)$ & $1.6(1.0-2.7)$ & NS & 1.4 & $-0.33 ; 3.13$ \\
\hline Bergen (2005) [38] & $2.0(1.7-2.3)$ & $1.5(1.1-1.9)$ & $2.5(2.0-3.0)$ & $P<0.001$ & -1.0 & $-1.60 ;-0.39+$ \\
\hline Götz (2005) [39] & $2.4(2.1-2.8)$ & $2.0(1.4-2.7)$ & $2.6(2.2-3.2)$ & OR $1.4 ; P=0.08$ & -0.6 & $-1.38 ; 0.18$ \\
\hline Macleod (2005) [40] & $3.0(2.3-3.9)$ & $2.8(2.2-3.4)$ & $3.6(3.1-4.9)$ & NS & -0.8 & $-1.81 ; 0.21$ \\
\hline Low (2007) [19] & NS & $5.3(4.4-6.3)$ & $6.2(4.9-7.8)$ & NS & -0.9 & $-2.51 ; 0.71$ \\
\hline Deblina Datta (2007) [41] & $2.2(1.8-2.8)$ & $2.0(1.6-2.5)$ & $2.5(1.8-3.4)$ & NS & -0.5 & $-1.21 ; 0.21$ \\
\hline Stein (2008) [42] & NS & $3.9(3.1-4.8)$ & $5.1(4.2-6.0)$ & NS & -1.2 & $-1.98 ;-0.43+$ \\
\hline Adams (2008) [43] & $11.3(8.4-14.2)$ & $12.1(7.7-16.5)$ & $10.6(6.7-14.5)$ & $P=0.643$ & 1.5 & $-4.75 ; 7.75$ \\
\hline Uusküla (2008) [44] & $5.4(3.0-7.5)^{*}$ & $2.7(0.3-5.0)^{*}$ & $6.9(3.6-10.3)^{*}$ & NS & -4.2 & $-7.64 ;-0.76+$ \\
\hline Beydoun (2010) [45] & $1.6(1.3-1.9)$ & 1.7 (NS) & 1.6 (NS) & $P=0.8$ & 0.1 & $-0.57 ; 0.77$ \\
\hline Imai (2010) [46] & NS & 6.7 (NS) & 9.5 (NS) & NS & -2.8 & $-4.12 ;-1.48+$ \\
\hline Goulet (2010) [47] & NS & $1.4(0.8-2.6)$ & $1.6(1.0-2.5)$ & NS & -0.2 & $-1.14 ; 0.74$ \\
\hline Parish (2011) [48] & NS & $2.1(1.3-3.3)^{*}$ & $2.6(1.6-4.1)^{*}$ & NS & -0.5 & $-1.72 ; 0.72$ \\
\hline Desai (2011) [28] & $0.9(0.5-1.3)$ & $0.1(0.0-0.3)$ & $1.8(0.9-2.6)$ & $P<0.001$ & -1.7 & $-2.61 ;-0.79+$ \\
\hline Bozicevic (2011) [49] & $6.2(3.3-9.1)$ & 7.3 (NS) & 5.3 (NS) & $P=0.491$ & 2.0 & $-3.82 ; 7.82$ \\
\hline Eggleston (2011) [50] & $3.9(2.8-5.0)$ & $4.5(2.4-6.5)$ & $3.4(2.2-4.6)$ & OR 0.6; $P=0.16$ & 1.1 & $-0.64 ; 2.84$ \\
\hline Gravningen (2012) [51] & $4.1(3.3-5.3)$ & $3.9(2.3-6.0)$ & $7.3(5.3-9.7)$ & NS & -3.4 & $-6.17 ;-0.63 \dagger$ \\
\hline Klovstad (2012) [52] & $5.5(4.5-6.8)$ & $5.1(3.8-6.8)$ & $5.8(4.5-6.8)$ & NS & -0.7 & $-3.01 ; 1.61$ \\
\hline
\end{tabular}

*: Prevalences after weighting for the population distribution.

t: statistically significant difference.

NS: Data not stated.

Cl: $95 \%$ confidence interval.

SE: Standard error.

younger participants had higher prevalence than older participants but this is the case for both men and women. Also, the prevalence of Chlamydia trachomatis in urban and rural areas did not differ between men and women. The review highlighted that chlamydia prevalence was highly variable between countries but with rates often as high in men as in women. The commonly held assumption that chlamydia infection is more prevalent in women than in men should therefore be reconsidered.

\section{Strengths and weaknesses of the study}

Two methodological issues need to be addressed as they may influenced the validity of these findings. Firstly, the majority of the studies had low or unspecified participation rates more for men than for women $(<60 \%)$.
A low participation rate can induce non-participation bias and the population sample under study may not be generalizable to the whole population [54]. Few studies collected data on non-respondents for comparison with respondernts to assess the implications of study nonparticipation. It is uncertain how and if non-participation bias influenced the results. Secondly, most studies used first voided urine in women instead of vulvovaginal swabs. Both specimens from women are suitable but the vulvovaginal swab is the specimen of choice in women [55]. The number of infections identified in women in the studies using first voided urine may have been higher when using a vulvovaginal swab. The sensitivity of first voided urine for the detection of chlamydia infection in women is lower than vaginal specimens. Last we did not address specific ethnic backgrounds in our review. 
Table 3 Results population-based studies reporting prevalence of Chlamydia trachomatis for sex related to age

\begin{tabular}{|c|c|c|c|c|c|c|}
\hline $\begin{array}{l}\text { Authors (publication year) } \\
\text { [Reference] }\end{array}$ & Age group & $\begin{array}{l}\text { Highest prevalence } \\
\text { by age in men }\end{array}$ & $\begin{array}{l}\text { Prevalence \% } \\
(95 \% \mathrm{CI})\end{array}$ & $\begin{array}{l}\text { Highest prevalence } \\
\text { by age in women }\end{array}$ & $\begin{array}{l}\text { Prevalence \% } \\
(95 \% \mathrm{Cl})\end{array}$ & $\begin{array}{l}\text { sex difference } \\
\text { by age }\end{array}$ \\
\hline Valkengoed (2000) [31] & $15-40$ & $21-25$ & $3.3(1.0-5.5)$ & $21-25$ & $4.4(2.6-6.3)$ & $\leftrightarrow$ \\
\hline Fenton (2001) [32] & $18-44$ & $25-34$ & $3.0(1.7-5.1)$ & $18-24$ & $3.0(1.7-5.0)$ & $\uparrow$ \\
\hline Obasi (2001) [33] & 15-19 & 18 & $1.8(1.0-2.8)$ & 19 & $3.2(2.2-4.5)$ & $\downarrow$ \\
\hline Turner(2002) [34] & $18-35$ & $18-20^{*}$ & 8.0 (SE 3.9) & $18-20^{*}$ & 8.0 (SE 3.9) & - \\
\hline Miller (2004) [35] & $18-26$ & $20-21^{*}$ & $4.7(3.6-6.2)$ & $20-21^{*}$ & $4.7(3.6-6.2)$ & - \\
\hline Joyee (2004) [36] & $15-45$ & $31-45$ & $2.1(0.0-5.0)$ & $31-35$ & $1.9(0.0-3.9)$ & $\uparrow$ \\
\hline Latif (2004) [37] & $18-49$ & ns & & ns & & - \\
\hline Klavs (2004) [29] & $13-67$ & $18-24$ & $4.1(2.2-7.4)$ & $18-24$ & $4.1(2.2-7.4)$ & $\leftrightarrow$ \\
\hline Bergen (2005) [38] & $15-29$ & $25-29$ & $4.1(2.1-6.2)$ & $15-19$ & $4.3(1.5-7.0)$ & $\uparrow$ \\
\hline Götz (2005) [39] & $15-29$ & $15-19^{*}$ & 3.1 & $15-19^{*}$ & 3.1 & - \\
\hline Macleod (2005) [40] & $16-39$ & $20-24$ & $5.3(4.4-6.3)$ & $20-24$ & $6.2(4.9-7.8)$ & $\leftrightarrow$ \\
\hline Low (2007) [19] & $16-24$ & ns & & ns & & - \\
\hline Deblina Datta (2007) [41] & $14-39$ & $20-29$ & $3.2(2.4-4.3)$ & $14-19$ & $4.6(3.7-5.8)$ & $\uparrow$ \\
\hline Stein (2008) [42] & $18-26$ & $18-24$ & $1.0(0.6-1.5)$ & $25-26$ & $2.1(1.3-3.5)$ & $\downarrow$ \\
\hline Adams (2008) [43] & 18-35 & $18-20^{*}$ & 19.8 & $18-20^{*}$ & 19.8 & - \\
\hline Uusküla (2008) [44] & $18-35$ & ns & & ns & & - \\
\hline Beydoun (2010) [45] & $14-39$ & $<25$ & 2.7 (SE 0.6) & $<25$ & 2.8 (SE 0.7) & $\leftrightarrow$ \\
\hline Imai (2010) [46] & 18-39 & 20 & 8.3 & 19 & 12.2 & - \\
\hline Goulet (2010) [47] & $18-44$ & $25-29$ & $2.7(0.8-8.0)$ & $18-24$ & $3.6(1.9-6.8)$ & $\uparrow$ \\
\hline Parish (2011) [48] & $20-64$ & $25-34$ & $3.9(1.8-8.2)$ & $35-44$ & $4.2(2.7-6.7)$ & $\downarrow$ \\
\hline Desai (2011) [28] & $12-17$ & ns & & 17 & 3.7 & - \\
\hline Bozicevic (2011) [49] & $18-25$ & ns & & ns & & - \\
\hline Eggleston (2011) [50] & $15-35$ & $15-19^{*}$ & $8.0(4.3-11.6)$ & $15-19^{*}$ & $8.0(4.3-11.6)$ & - \\
\hline Gravningen (2012) [51] & $15-20$ & $19-20$ & 7.1 & $19-20$ & 11.1 & $\leftrightarrow$ \\
\hline Klovstad (2012) [52] & $18-25$ & $18-21$ & $6.3(3.9-10.0)$ & $18-21$ & $6.6(4.7-9.3)$ & $\leftrightarrow$ \\
\hline
\end{tabular}

*: Reported by age only, not age and sex.

ns: Data not stated.

$\leftrightarrow:$ No sex difference in Chlamydia prevalence related to age.

$\uparrow$ : Chlamydia prevalence related to age highest in men.

$\downarrow$ : Chlamydia prevalence related to age highest in women.

Few studies presented chlamydia infection by ethnical background. Ethnicity is a known risk factor for STIs [34,35].

The strengths of this review are that, in our opinion, it provides the most comprehensive review to date of chlamydia prevalence estimates in the general population directly comparing men and women. We conducted comprehensive literature searches of multiple databases and used rigorous methods to appraise the articles. It is unlikely that we excluded important articles in this field. All studies used the nucleic acid amplification test with high sensitivity and specificity not only greatly enhancing the acceptability of a screening intervention but also increasing the reliability of the prevalence estimates. It is the first review in this area to confirm the previous conclusions in other systematic reviews of chlamydia prevalence estimates in non-population-based studies that the prevalence of urogenital chlamydia infections is as high in men as in women [16,24,25].

\section{Implications}

It is clear from this review that men are also an important reservoir of chlamydia infection for women and as such men should also be targeted for chlamydial screening. The vulnerability of women for a urogenital chlamydia infection in different countries did not emerge as a robust trend in this review of the literature. The reason for the reported sex differences are explained in the literature as artefacts or bias of reporting and the fact that women are more studied and more tested than men $[16,24,25]$. Chlamydia screening is frequently performed in women even in the absence of symptoms for example in routine gynaecologic care, Pap test, IUD insertion or unintended pregnancy, and it is more common to perform 
population-based chlamydia screening activities for women $[13,14]$. By contrast, fewer men are diagnosed in primary care: men are often treated for chlamydia without a definitive diagnosis, based upon symptoms such as urethritis or being a contact of a women with a chlamydia infection [56,57]. Also this review shows that men consistently have lower participation rates in chlamydia prevalence studies. The results of this study confirm and strongly support the need for higher coverage of men in chlamydia screening and research activities $[4,24]$.

The conclusion from this review is that the prevalence of chlamydia infection in men and women in the general population is more similar rather than dissimilar regardless of age or level of urbanisation. According to the literature, many factors shape women's and men's risks for chlamydia infection differently $[22,23,58]$. Biological predisposition and certain gender-specific behaviours are mentioned in the literature as possible reasons for women being more at risk for chlamydia and other STIs than men [58,59]. For example, cervical ectopy, especially in young women, may increase their susceptibility to chlamydia infection. Cervical ectopy is more common in women using oral contraceptives [60]. Hormonal contraceptives are associated with an increased risk of chlamydia infection [60-62]. Vaginal douching is associated with bacterial vaginosis and HIV, both increasing the risk for other STIs [63]. A direct association between douching and chlamydia is less consistent [64]. In the male however, little is known about analogous phsysiological changes that might affect a man's risk of infection with chlamydia. Circumcision in men, not in women, appears to reduce the risk of acquiring STI [65]. Men tend disproportionately to place monogamous women at risk for STI [58]. All this may be true, in the general population it seems to result in a modest difference in the prevalence of chlamydia among men and women only.

\section{Conclusion}

We found modest sex differences in prevalence rates amongst general populations but the prevalence of chlamydia infection in men and women is more similar than they are dissimilar. The prevalence of Chlamydia trachomatis in population-based studies ranges from $0.1 \%$ to $12.1 \%$ in men and from $1.1 \%$ to $10.6 \%$ in women depending upon age and country. The prevalence rates can be used to inform chlamydia screening strategies in general practice in men and women given that the most serious long term consequence of chlamydia for individual women, infertility, is one that will ultimately affect also men.

\section{Competing interests}

The author(s) declare that they have no competing interests. The authors alone are responsible for the content and writing of the paper.

\section{Authors' contribution}

PD was responsible for the data collection, data analysis, interpretation and writing the paper. DT contributed to the data collection and data analysis. All authors were responsible for the study design, interpretation and

commenting on drafts of the paper. All authors have read and approved the final manuscript.

\section{Author details}

'Department of Primary care and Community Care, Radboud University medical center, P.O. Box 9101, Nijmegen 6500HB, The Netherlands. ${ }^{2}$ Gender and Women's Health, Radboud University medical center, Nijmegen, The Netherlands.

Received: 13 August 2013 Accepted: 1 November 2013

Published: 11 November 2013

\section{References}

1. Cook RL, Hutchison SL, Ostergaard L, Braithwaite RS, Ness RB: Systematic review: noninvasive testing for Chlamydia trachomatis and Neisseria gonorrhoeae. Ann Intern Med 2005, 142:914-925.

2. Haggerty CL, Gottlieb SL, Taylor BD, Low N, Xu F, Ness RB: Risk of sequelae after Chlamydia trachomatis genital infection in women. J Infect Dis 2010, 201(Suppl 2):S134-155.

3. Wallace LA, Scoular A, Hart G, Reid M, Wilson P, Goldberg DJ: What is the excess risk of infertility in women after genital chlamydia infection? a systematic review of the evidence. Sex Transm Infect 2008, 84:171-175.

4. Cunningham KA, Beagley KW: Male genital tract chlamydial infection: implications for pathology and infertility. Biol Reprod 2008, 79:180-189.

5. Wagenlehner FM, Naber KG, Weidner W: Chlamydial infections and prostatitis in men. BJU Int 2006, 97:687-690.

6. Lorimer K, Hart GJ: Knowledge of Chlamydia trachomatis among men and women approached to participate in community-based screening, Scotland, UK. BMC Public Health 2010, 10:794.

7. Samkange-Zeeb FN, Spallek L, Zeeb H: Awareness and knowledge of sexually transmitted diseases (STDs) among school-going adolescents in Europe: a systematic review of published literature. BMC Public Health 2011, 11:727.

8. Trent M, Millstein SG, Ellen JM: Gender-based differences in fertility beliefs and knowledge among adolescents from high sexually transmitted disease-prevalence communities. J Adolesc Health 2006, 38:282-287.

9. Gift TL, Blake DR, Gaydos CA, Marrazzo JM: The cost-effectiveness of screening men for Chlamydia trachomatis: a review of the literature. Sex Transm Dis 2008, 35:S51-60.

10. Low N, Cassell JA, Spencer B, Bender N, Hilber AM, van Bergen J, Andersen B, Herrmann B, Dubois-Arber F, Hamers FF, et al: Chlamydia control activities in Europe: cross-sectional survey. Eur J Public Health 2012, 22:556-561.

11. Shaw K, Stephens N, Coleman D, O'Sullivan M: Role of the general practitioner in testing for genital Chlamydia trachomatis infection: an analysis of enhanced surveillance data. Sex Health 2009, 6:208-212.

12. van Bergen JE, Kerssens JJ, Schellevis FG, Sandfort TG, Coenen TT, Bindels PJ: Sexually transmitted infection health-care seeking behaviour in the Netherlands: general practitioner attends to the majority of sexually transmitted infection consultations. Int J STD AIDS 2007, 18:374-379.

13. Roberts TE, Robinson S, Barton P, Bryan S, Low N, Chlamydia Screening Studies G: Screening for Chlamydia trachomatis: a systematic review of the economic evaluations and modelling. Sex Transm Infect 2006, 82:193-200. discussion 201.

14. Workowski KA, Berman S, Centers for Disease C, Prevention: Sexually transmitted diseases treatment guidelines, 2010. MMWR Recomm Rep 2010, 59:1-110.

15. Gottlieb SL, Berman SM, Low N: Screening and treatment to prevent sequelae in women with Chlamydia trachomatis genital infection: how much do we know? J Infect Dis 2010, 201(Suppl 2):S156-167.

16. Vajdic CM, Middleton M, Bowden FJ, Fairley CK, Kaldor JM: The prevalence of genital Chlamydia trachomatis in Australia 1997-2004: a systematic review. Sex Health 2005, 2:169-183.

17. Wilson JS, Honey E, Templeton A, Paavonen J, Mardh PA, Stray-Pedersen B, Group EUBCA: A systematic review of the prevalence of Chlamydia trachomatis among European women. Hum Reprod Update 2002, 8:385-394.

18. Bender N, Herrmann B, Andersen B, Hocking JS, van Bergen J, Morgan J, van den Broek IV, Zwahlen M, Low N: Chlamydia infection, pelvic 
inflammatory disease, ectopic pregnancy and infertility: cross-national study. Sex Transm Infect 2011, 87:601-608.

19. Low N, McCarthy A, Macleod J, Salisbury C, Campbell R, Roberts TE, Horner P, Skidmore S, Sterne JA, Sanford E, et al: Epidemiological, social, diagnostic and economic evaluation of population screening for genital chlamydial infection. Health Technol Assess 2007, 11(iii-iv, ix-xii):1-165.

20. Salisbury C, Macleod J, Egger M, McCarthy A, Patel R, Holloway A, Ibrahim F, Sterne JA, Horner P, Low N: Opportunistic and systematic screening for chlamydia: a study of consultations by young adults in general practice. Br J Gen Pract 2006, 56:99-103.

21. van Bergen JE, Fennema JS, van den Broek IV, Brouwers EE, de Feijter EM, Hoebe CJ, Koekenbier RH, de Coul EL, van Ravesteijn SM, Gotz HM: Rationale, design, and results of the first screening round of a comprehensive, register-based. Chlamydia screening implementation programme in the Netherlands. BMC Infect Dis 2010, 10:293.

22. Madkan VK, Giancola AA, Sra KK, Tyring SK: Sex differences in the transmission, prevention, and disease manifestations of sexually transmitted diseases. Arch Dermatol 2006, 142:365-370.

23. Wong T, Singh A, Mann J, Hansen L, McMahon S: Gender differences in bacterial STIs in canada. BMC Womens Health 2004, 4(1):26.

24. Adams EJ, Charlett A, Edmunds WJ, Hughes G: Chlamydia trachomatis in the United Kingdom: a systematic review and analysis of prevalence studies. Sex Transm Infect 2004, 80:354-362.

25. Lewis D, Newton DC, Guy RJ, Ali H, Chen MY, Fairley CK, Hocking JS: The prevalence of Chlamydia trachomatis infection in Australia: a systematic review and meta-analysis. BMC Infect Dis 2012, 12:113

26. Vandenbroucke JP, von Elm E, Altman DG, Gotzsche PC, Mulrow CD, Pocock SJ, Poole C, Schlesselman JJ, Egger M, Initiative S: Strengthening the reporting of observational studies in epidemiology (STROBE): explanation and elaboration. PLoS Med 2007, 4:e297.

27. Silva LCO P, Rodriguez MP, Robles S: A tool for assessing the usefulness of prevalence studies done for surveillance purposes: the example of hypertension. Pan Am J Public Health 2001, 10:9.

28. Desai S, Meyer T, Thamm M, Hamouda O, Bremer V: Prevalence of Chlamydia trachomatis among young German adolescents, 2005-06. Sex Health 2011, 8:120-122

29. Klavs I, Rodrigues LC, Wellings K, Kese D, Hayes R: Prevalence of genital Chlamydia trachomatis infection in the general population of Slovenia: serious gaps in control. Sex Transm Infect 2004, 80:121-123.

30. Altman DG, Gardner MJ: Confidence intervals for research findings. Br J Obstet Gynaecol 1992, 99:90-91.

31. van Valkengoed IG, Morre SA, van den Brule AJ, Meijer CJ, Deville W, Bouter $L M$, Boeke AJ: Low diagnostic accuracy of selective screening criteria for asymptomatic Chlamydia trachomatis infections in the general population. Sex Transm Infect 2000, 76:375-380.

32. Fenton KA, Korovessis $C$, Johnson AM, McCadden A, McManus S, Wellings $K$, Mercer CH, Carder C, Copas AJ, Nanchahal K, et al: Sexual behaviour in Britain: reported sexually transmitted infections and prevalent genital Chlamydia trachomatis infection. Lancet 2001, 358:1851-1854.

33. Obasi Al, Balira R, Todd J, Ross DA, Changalucha J, Mosha F, Grosskurth H, Peeling R, Mabey DC, Hayes RJ: Prevalence of HIV and Chlamydia trachomatis infection in 15-19-year olds in rural Tanzania. Trop Med Int Health 2001, 6:517-525.

34. Turner CF, Rogers SM, Miller HG, Miller WC, Gribble JN, Chromy JR, Leone PA, Cooley PC, Quinn TC, Zenilman JM: Untreated gonococcal and chlamydial infection in a probability sample of adults. JAMA 2002, 287:726-733.

35. Miller WC, Ford CA, Morris M, Handcock MS, Schmitz JL, Hobbs MM, Cohen MS, Harris KM, Udry JR: Prevalence of chlamydial and gonococcal infections among young adults in the United States. JAMA 2004, 291:2229-2236.

36. Joyee AG, Thyagarajan SP, Rajendran P, Hari R, Balakrishnan P, Jeyaseelan L, Kurien T, Group STDS: Chlamydia trachomatis genital infection in apparently healthy adult population of Tamil Nadu, India: a population-based study. Int J STD AIDS 2004, 15:51-55.

37. Latif AS K: STI screening conducted in NT Department of health and community services and community controlled health services in central Australia in 2004. The Northern Territory Disease Control Bulletin 2004, 11:3.

38. van Bergen J, Gotz HM, Richardus JH, Hoebe CJ, Broer J, Coenen AJ, group PCs: Prevalence of urogenital Chlamydia trachomatis increases significantly with level of urbanisation and suggests targeted screening approaches: results from the first national population based study in the Netherlands. Sex Transm Infect 2005, 81:17-23.
39. Gotz HM, van Bergen JE, Veldhuijzen IK, Broer J, Hoebe CJ, Steyerberg EW, Coenen AJ, de Groot F, Verhooren MJ, van Schaik DT, Richardus JH: A prediction rule for selective screening of Chlamydia trachomatis infection. Sex Transm Infect 2005, 81:24-30.

40. Macleod J, Salisbury C, Low N, McCarthy A, Sterne JA, Holloway A, Patel R, Sanford E, Morcom A, Horner P, et al: Coverage and uptake of systematic postal screening for genital Chlamydia trachomatis and prevalence of infection in the United Kingdom general population: cross sectional study. BMJ 2005, 330:940.

41. Datta SD, Sternberg M, Johnson RE, Berman S, Papp JR, McQuillan G, Weinstock H: Gonorrhea and chlamydia in the United States among persons 14 to 39 years of age, 1999 to 2002. Ann Intern Med 2007, 147:89-96.

42. Stein CR, Kaufman JS, Ford CA, Leone PA, Feldblum PJ, Miller WC: Screening young adults for prevalent chlamydial infection in community settings. Ann Epidemiol 2008, 18:560-571.

43. Adams OP, Carter AO, Prussia P, Mclntyre G, Branch SL: Risk behaviour, healthcare access and prevalence of infection with Chlamydia trachomatis and Neisseria gonorrhoeae in a population-based sample of adults in Barbados. Sex Transm Infect 2008, 84:192-194.

44. Uuskula A, Kals M, Denks K, Nurm U, Kasesalu L, Dehovitz J, McNutt LA: The prevalence of chlamydial infection in Estonia: a population-based survey. Int J STD AIDS 2008, 19:455-458.

45. Beydoun HA, Dail J, Tamim H, Ugwu B, Beydoun MA: Gender and age disparities in the prevalence of Chlamydia infection among sexually active adults in the United States. J Womens Health (Larchmt) 2010, 19:2183-2190.

46. Imai H, Nakao H, Shinohara H, Fujii Y, Tsukino H, Hamasuna R, Osada $Y$, Fukushima K, Inamori M, Ikenoue T, Katoh T: Population-based study of asymptomatic infection with Chlamydia trachomatis among female and male students. Int J STD AIDS 2010, 21:362-366.

47. Goulet V, de Barbeyrac B, Raherison S, Prudhomme M, Semaille C, Warszawski J, group CSF: Prevalence of Chlamydia trachomatis: results from the first national population-based survey in France. Sex Transm Infect 2010, 86:263-270.

48. Parish WL, Laumann EO, Cohen MS, Pan S, Zheng H, Hoffman I, Wang T, Ng $\mathrm{KH}$ : Population-based study of chlamydial infection in China: a hidden epidemic. JAMA 2003, 289:1265-1273.

49. Bozicevic I, Grgic I, Zidovec-Lepej S, Cakalo II, Belak-Kovacevic S, Stulhofer A, Begovac J: Urine-based testing for Chlamydia trachomatis among young adults in a population-based survey in Croatia: feasibility and prevalence. BMC Public Health 2011, 11:230.

50. Eggleston E, Rogers SM, Turner CF, Miller WC, Roman AM, Hobbs MM Erbelding E, Tan S, Villarroel MA, Ganapathi L: Chlamydia trachomatis infection among 15- to 35-year-olds in Baltimore, MD. Sex Transm Dis 2011, 38:743-749.

51. Gravningen K, Furberg AS, Simonsen GS, Wilsgaard T: Early sexual behaviour and Chlamydia trachomatis infection - a population based cross-sectional study on gender differences among adolescents in Norway. BMC Infect Dis 2012, 12:319.

52. Klovstad H, Grijibovski A, Aavitsland P: Population based study of genital Chlamydia trachomatis prevalence and associated factors in Norway: a cross sectional study. BMC Infect Dis 2012, 12:150.

53. Underhill G, Hewitt G, McLean L, Randall S, Tobin J, Harindra V: Who has chlamydia? The prevalence of genital tract Chlamydia trachomatis within Portsmouth and South East Hampshire, UK. J Fam Plann Reprod Health Care 2003, 29:17-20.

54. Galea S, Tracy M: Participation rates in epidemiologic studies. Ann Epidemiol 2007, 17:643-653.

55. Falk L, Coble Bl, Mjornberg PA, Fredlund H: Sampling for Chlamydia trachomatis infection - a comparison of vaginal, first-catch urine, combined vaginal and first-catch urine and endocervical sampling. Int J STD AIDS 2010, 21:283-287.

56. Cassell JA, Mercer CH, Fenton KA, Copas AJ, Erens B, Wellings K, Johnson AM: A comparison of the population diagnosed with chlamydia in primary care with that diagnosed in sexual health clinics: implications for a national screening programme. Public Health 2006, 120:984-988.

57. Mercer $\mathrm{CH}$, Sutcliffe L, Johnson AM, White PJ, Brook G, Ross JD, Dhar J, Horner $P$, Keane F, Jungmann E, et al: How much do delayed healthcare seeking, delayed care provision, and diversion from primary care contribute to the transmission of STIs? Sex Transm Infect 2007, 83:400-405. 
58. Hook EW 3rd: Gender differences in risk for sexually transmitted diseases. Am J Med Sci 2012, 343:10-11.

59. Higgins JA, Hoffman S, Dworkin SL: Rethinking gender, heterosexual men, and women's vulnerability to HIV/AIDS. Am J Public Health 2010, 100:435-445.

60. Bright PL, Norris Turner A, Morrison CS, Wong EL, Kwok C, Yacobson I, Royce RA, Tucker HO, Blumenthal PD: Hormonal contraception and area of cervical ectopy: a longitudinal assessment. Contraception 2011, 84:512-519.

61. Morrison CS, Turner AN, Jones LB: Highly effective contraception and acquisition of HIV and other sexually transmitted infections. Best Pract Res Clin Obstet Gynaecol 2009, 23:263-284.

62. Morrison CS, Bright P, Wong EL, Kwok C, Yacobson I, Gaydos CA, Tucker HT, Blumenthal PD: Hormonal contraceptive use, cervical ectopy, and the acquisition of cervical infections. Sex Transm Dis 2004, 31:561-567.

63. Cottrell BH: An updated review of of evidence to discourage douching. MCN Am J Matern Child Nurs 2010, 35:102-107. quiz 108-109.

64. Ness RB, Hillier SL, Kip KE, Richter HE, Soper DE, Stamm CA, McGregor JA Bass DC, Rice P, Sweet RL: Douching, pelvic inflammatory disease, and incident gonococcal and chlamydial genital infection in a cohort of high-risk women. Am J Epidemiol 2005, 161:186-195.

65. Weiss HA: Male circumcision as a preventive measure against HIV and other sexually transmitted diseases. Curr Opin Infect Dis 2007, 20:66-72.

doi:10.1186/1471-2334-13-534

Cite this article as: Dielissen et al.: Chlamydia prevalence in the general population: is there a sex difference? a systematic review. BMC Infectious Diseases 2013 13:534.

\section{Submit your next manuscript to BioMed Central and take full advantage of:}

- Convenient online submission

- Thorough peer review

- No space constraints or color figure charges

- Immediate publication on acceptance

- Inclusion in PubMed, CAS, Scopus and Google Scholar

- Research which is freely available for redistribution 